\title{
The Effects of Video Clips Enrichment to the Academic Performance of Grade 8 Learners in Earth and Space Science
}

\author{
Arsad S. Pumbaya ${ }^{1}$, Asliah B. Pumbaya ${ }^{2}$ \\ ${ }^{1 \& 2}$ Mindanao State University - Integrated Laboratory School \\ Marawi City, Lanaodel Sur, Mindanao, Philippines
}

\begin{abstract}
This study investigated the effects of video clips enrichment on the academic performance of Grade 8 learners in Earth and Space Science. This was conducted in MSU-ILS, MSU Campus, Marawi City, during the school year 2018-2019. The study employed the quasi-experimental non-equivalence pretest-posttest research design to test the effects of the video clips enrichment on the academic performance of Grade Eight learners. The academic performance of the two groups was assessed using the research-made 30-item multiple-choice test which has a reliability coefficient of 0.74 , indicating that it was reliable and dependable to assess the academic performance of the learners. The data were treated with mean, standard deviation, and ANCOVA (Analysis of Covariance) at 0.05 level of significance. Moreover, the experiences of the learners in learning Earth and Space Science with video clips enrichment using their entries from the journal notebook and scheduled interview was administered after the conduct of the lesson and the post test. Results revealed that the learners taught with video clips enrichment in Earth and Space Science had a "very satisfactory" academic performance. This means that the learners at this level have developed the basic knowledge, skills and main understandings and can transfer them separately through genuine performance tasks. There is also a significant difference between the mean gain scores of the academic performance of Grade 8 learners taught with video clips enrichment and taught with $K$ to 12 learning modules after the intervention, hence, the experimental group achieved significant growth in conceptual understanding which could be attributed to the use of video clips. The experimental group have gained positive experiences as it made them excited, attentive, and participative in class which could have resulted to their better academic performance in the subject. Therefore, the use of video clips in science lessons could enhance the academic performance of the learners.
\end{abstract}

Keywords—video clips, enrichment, multimedia, earth science, space science

\section{INTRODUCTION}

The use of technology inside the classroom is implicated in almost every part of our culture. It affects how we think, live, work, play, and most importantly learn. With technology becoming an increasing requirement across every industry today, it only makes sense that our schools are also effectively deploying technology in the classroom.

Technology is used as an integrative tool to enhance, reiterate, present, and assess how students understand the syllabus or the program (Edutopia, 2005). It ranges from the basic notion of tool, to systems which employ or exploit technologies and there is a need for the Higher Education to look for ways to use these tools to connect groups and create systems (Bates, 2015). These include video clips, films, audio tapes, music videos and graphics also known as multimedia technologies that could help increase the academic performance of the learners. Moreover, technology supports both teaching and learning.

Video clips are short episodes of recorded video material that delivers facts and concepts in various approaches of presentation. The presentation would be verbal, pictorial, movement, sound, and headings through a simultaneous sensory channel of aural and visual of the human brain (Mayer, 2001). Video clips boost learners' creativity and cooperation. It helps motivate learners and create a diverse context for their learning experience. It also influences Internet-based digital video to enhance self-directed learning (Greenberg, et al., 2012). It gives illustration, demonstrations, specimens, and the environment of real-life activities brought to the learners in a neat and exciting package (Isiaka, 2007).

According to Prensky (2001), today's learners think and process information that is fundamentally different from their predecessors. Learners who are in high school today belong to a generation of Digital Natives where computers are a common part of their lives. Moreover, today's teens are spending more than onethird of their days, nearly nine hours on average in watching online video or listening to music. This new generation of learners has hypertext mindset because of the instant gratification of the nature of the internet 
having immediate answers to a phenomenon (Berge, 2008). Much more, seventy-eight percent of the parents from the Kaiser Family Report trust the educational value of their children's media interaction (Ontoy,2012).

In contrary to the cited circumstances, problems in teaching and learning process in Science emerge. The Science education in the Philippines is considered as weak. In the 2014 National Achievement Test (NAT) results, the passing rate for high school seems worse with only $46.38 \%$. The country also showed an extremely poor performance in international surveys such as Trends in International Mathematics and Science Study (TIMSS) and ranked only $43^{\text {rd }}$ out of the 46 participating countries in High School Science. The statistical data confirmed that the rising problem in science education must be address instantaneously.

At MSU-ILS where the researcher is currently connected, shortage of classrooms and lack of Science laboratories and equipment to facilitate Science learning and application of its concepts to learners were the common problems observed. There is also a challenge in terms of the quality of its textbooks with numerous errors in the draft copy of the 2013 Grade 8 Science Learner's Materials. In addition, it is observed that the learners in Grade 8 had different academic scores and less amount of attention is given to the lesson when methods of teaching are not appropriate. Moreover, it has been observed that it is difficult to explain the exact visualization on some topics in Earth and Space Science like faults and earthquakes. It is in this matter that the teacher-researcher sought teaching-intervention to this situation.

The situation cited would suggest that using video clips are beneficial to learners. Video clips help them to be more attentive and responsive. It elicits superficial and even deep feelings and emotions such as excitement, anger, laughter, relaxation, love, whimsy, or even boredom. It gives a powerful effect on one's mind and senses and provides a cognitive and emotional impact. Therefore, video clips could be adopted in the classroom as a facet of instruction together with the other instructional materials prepared for the given lesson (Griffin, 1998).

Research has shown (Enger, 1976; Savenye, 1989) that video media provides for (a) the capture of uncommon and hard-to-duplicate material and phenomena; (b) the ability to present static and moving material; (c) the alteration of visual, auditory, and temporal characteristics of video media and phenomena; and (d) the option to incorporate animation for added clarity.

Selecting efficient video clips is an essential component of integrating this medium into practice and realizing the promise of multimedia in the classroom. Fabos (2001) mentioned that success or failure in the use of educational technology depends on the quality of the content, not on the technology itself. To maximize the effectiveness of video clips, the critical element that needs to be considered is its strength and its visually-rich educational content. If used prudently, video clips have the potential of making a positive influence on learner's performance in Science.

Performance in science subject is still very poor among learners at the secondary level. One of the identified causes of the problem is the teaching method used by Science teachers such as the traditional ones. It is then perceived that the teaching method employed by the teachers in the field may not be appropriate to the teaching style preference of these digital native learners. Thus, these situations prompted the researcher to investigate the effects of video clips enrichment to the academic performance of Grade 8 learners in Earth and Space Science lessons.

This study investigated the effects of the video clips enrichment to the academic performance of Grade 8 learners in Earth and Space Science in MSU-ILS during the $2^{\text {nd }}$ quarter of the School Year 20182019.Specifically, this study sought an answer to the following:1. Is there a significant difference between the Pretest and the Posttest scores of the Grade 8 learners taught with video clips enrichment and with $\mathrm{K}$ to 12 learning modules?'; 2. Is there a significant difference between the mean gain scores of the academic performance of Grade 8 learners taught with video clips enrichment and with $\mathrm{K}$ to 12 learning modules after the intervention?; and 3. What are the experiences of Grade 8 Learners in learning Earth and Space Science with video clips enrichment?

\section{Research Design}

\section{METHODS}

This study used a quasi-experimental non-equivalence pretest-posttest research design. There is a treatment group that is given a pretest, receives a treatment, and is given a posttest. At the same time, a nonequivalent control group is given a pretest, does not receive the treatment, and is given a posttest. This study focused on the effects of video clips enrichment to the academic performance of Grade 8 learners in Earth and Space Science.

The study used a static group. In selecting the participants, the learners were paired according to their academic performance in the first grading period. Before the lessons were conducted by the researcher, they were given a pretest first. The experimental group was to be taught using video clips enrichment while the 
control group made use of K to 12 learning modules. Both groups were given a posttest by the teacher after the conduct of the lessons.

\section{Research Locale}

This study conducted at the Mindanao State University - Integrated Laboratory School (MSU-ILS), MSU Campus, Marawi City was primarily known as Laboratory Elementary School (LES). On September 9, 1964, the school was established to meet the educational training needs of the children and dependents of the faculty and employees of the university. Later a pre-elementary education was created. Then the University BOR Resolution No. 1522 Series of 1978 approved the expansion of the education program with a fourth-year high school general education. It is known at present as the Integrated Laboratory School. It performs two functions: as a laboratory school for the College of Education and other colleges and as a service function to the children and dependents of MSU Faculty and other personnel. Nearby places such as Marantao, Balindong, Tugaya, Piagapo, and Saguiaran surrounds the school.

\section{Participants of the Study}

The participants of this study were the grade 8 learners of Mindanao State University-Integrated Laboratory School. The study used two intact classes. The researcher chose the two middle sections since the school used a heterogeneous grouping. The researcher randomly assigned the Grade 8-Wolffia as the control group while Grade 8-Venus Flytrap was chosen as the experimental group. The participants of the study were officially enrolled Grade 8 Learners, S.Y. 2018-2019 in MSU-ILS of the K to 12 Curriculum. Each section was composed of 30 learners grouped upon enrolment and were matched according to their Science grades during the first grading period of the school year 2018-2019.

\section{Research Instruments}

The research instruments used in the data gathering are the Earth and Space Science Academic Performance Test and the use of video clips enrichment.

The researcher constructed the Earth and Space Science Academic Performance Test. It was tried-out to Grade 8 learners of Philippine Integrated School, Inc. and was subjected to item analysis using the U-L Index Method, deciding whether to retain or reject a test question based on two ranges. Taken were items with difficulty indices within less than 0.3 and discrimination indices within greater than or equal to 0.3 . The use of video clips was also utilized to determine the effects of video clips enrichment to the academic performance of the learners.

\section{Earth and Space Science Academic Performance Test}

In the development of the test, a table of specification (TOS) was prepared by the researcher as the basis for the formulation of questions. The test items were thirty-pencil and paper test for both the control group and the experimental group. Before the conduct of the study, the reliability and dependability of the assessment were considered by the researcher to assess the academic performance in the selected topics in Earth and Space Science. The academic performance test had a reliability coefficient of 0.74 after the tryout, indicating that the test was reliable to measure the learners' academic performance. The test was intended to assess the academic performance in Earth and Space Science of the grade eight learners. The K to 12 Curriculum guide provided by the Department of Education served as the basis of it.

\section{Video Clips Enrichment}

Downloaded from YouTube were selected video clips on topics about earthquakes, faults, tsunami, and typhoons. These video clips were validated by experts using the DepEd LRMDS Assessment and Evaluation Tool based on the following criteria namely clarity, sound effects, and content. The panel of experts gave it a rating of "very satisfactory".

\section{Scoring for the Academic Performance Test}

The researcher followed the DepEd Order No.8 S. 2015 in the scoring procedures. The two groups were given two tests (pretest and posttest) where each result was categorized into its specific performance levels. That is, outstanding, very satisfactory, satisfactory, fairly satisfactory and did not meet expectations. 


\begin{tabular}{lll}
\hline Score Range & Performance Level & *Qualifying Statement \\
\hline $28-30$ & Outstanding & The students at this level exceed the core \\
& requirements regarding to knowledge, skills and \\
& understandings and can transfer them \\
& automatically and flexibility through authentic \\
& performance tasks
\end{tabular}

The students at this level have developed the fundamental knowledge and skills and core understanding and can transfer them independently through authentic performance tasks.

22-24 Satisfactory

The students at this level have developed the basic knowledge and skills and core understandings and with little guidance from the teacher and with some assistance from peers, can transfer these understandings through authentic performance tasks.

19-21 Fairly Satisfactory

The students at this level possess the minimum knowledge and skills and core understandings but need help throughout the performance of authentic tasks.

0-18 Did not Meet Expectation

The student at this level struggles with their understandings; prerequisites and fundamental knowledge and skills have not been acquired or developed adequately to aid understanding.

*Qualifying Statements is adopted from DepEd Order No. 73, S. 2012

\section{H. Data Gathering Procedure}

In gathering the data, an ethical process was being followed by the researcher. Following the protocol, the permission was secured from the Assistant Dean of MSU-Integrated Laboratory School of Marawi City to conduct a study with the endorsement and recommendation of the thesis adviser and Dean of the College of Education of Bukidnon State University.

The researcher handled the two heterogeneous classes for the conduct of the study. The purposes of the study were oriented to the two groups. Classes started after the briefing on the purpose of the study. Before the lesson proper, 30-item validated researcher-made academic performance test was given to both groups and served as the pretest. The treatment phase started with the use of video clips enrichment for the experimental groups; then the control group was taught via the $\mathrm{K}$ to 12 learning modules. The topics for both the experimental and the control group were the same throughout the class.

A 30-item validated researcher-made achievement posttest was given by the researcher at the last part of the treatment phase to both groups. The respondents took the same set of tests.

\section{FINDINGS}

\section{Academic Performance in Earth and Space Science of the Experimental Group and the Control Group}

The academic performance in Earth and Space Science between the experimental group and the control group was tested using the mean and the standard deviation. Table 1 shows the results in the academic performance between the experimental group and the control group. The pretest and posttest means scores in the performance test of the two groups were tested using the Levene's Test and T-Test independent sample. The experimental group was taught using video clips enrichment. However, the teacher used the K to 12 learning modules to the control group. 
Table 1

Academic Performance of Grade 8 Learners Taught with Video Clips Enrichment and with K to 12 Learning Modules

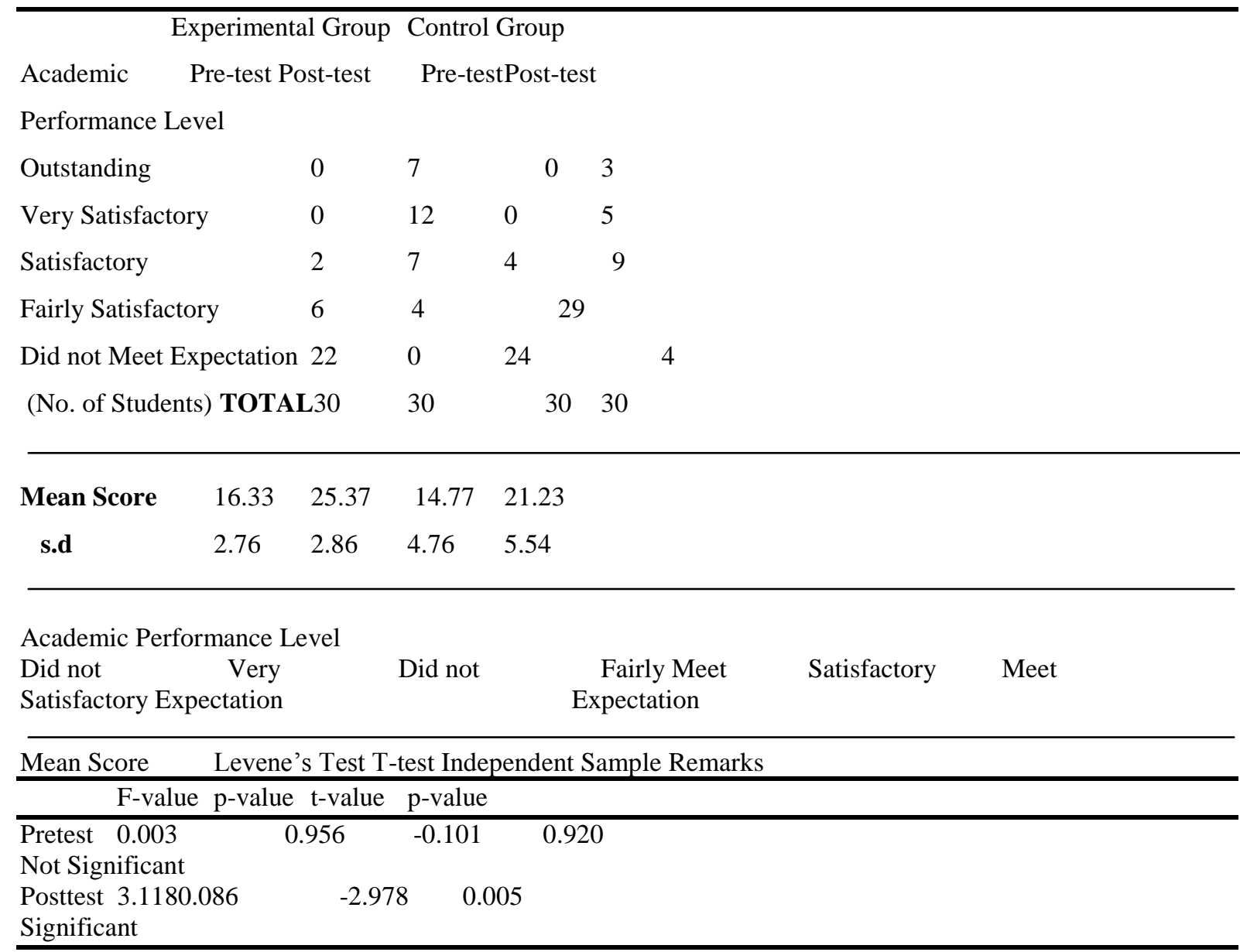

Table 1 shows that in the pretest, the range of score of the experimental group was from "did not meet expectation" to "satisfactory". Furthermore, these clustered in "did not meet expectation" level. The mean of the pretest in the experimental group indicates an academic performance level of "did not meet expectation". It confirms that the learners at this level struggles with his or her understandings; prerequisites and fundamental knowledge and skills have not been obtained or developed effectively. The experimental group's posttest scores clustered in the "fairly satisfactory" to "outstanding" academic performance. They obtained "very satisfactory" performance in the posttest after having used the video clips enrichment integrated in the lessons. It confirmed that the learners at this level have developed the fundamental knowledge and skills and core understanding and can shift them independently through authentic performance tasks.

In the control group, the pretest score ranged from "did not meet expectation" to "satisfactory" and clustered in "did not meet expectation". The mean academic performance score in the pretest of the control group is "did not meet expectation". It confirms that the learners at this level struggles with his or her understandings; prerequisites and basic knowledge and skills have not been obtained or developed sufficiently to help understanding. The posttest of the control group ranged from "did not meet expectation" to "outstanding" and clustered in "fairly satisfactory" and "satisfactory" levels. The mean score of the control group indicates that they had "fairly satisfactory" performance in the posttest which shows that the learners at this level possess the minimum knowledge, skilss, and core understandings and needs help throughout the performance of authentic tasks.

Table 1 also shows that in the performance test, the pretest means scores, results implied that the two groups of learners were comparable. Levene's Test was used to check whether the two groups are similar. The null hypothesis (for Levene's Test) Ho: Variances of the two groups are the same. Ho is not rejected based on Table 1 (means between pretest of the two groups). The test statistic used in not rejecting Ho is the F-test and 
the result is not significant. Thus, it can be concluded that the two groups have the same variance, and therefore, the two groups were comparable at the start of the intervention.

Having the same variance, the researcher proceeded to compare the mean of the two groups. Thus, the null hypothesis: There is no significant difference between the pretest mean scores of the academic performance of Grade 8 learners taught with video clips enrichment and taught with $\mathrm{K}$ to 12 learning modules before the intervention is not rejected. Therefore, the result is not significant. It means on the average, the academic performance of students based on their pretest scores were the same.

This was a good start for the research because the experimental and control group were comparable and on the same footing before the intervention.

The means between the posttest of the two groups indicating that the null hypothesis is NOT rejected was also shown. The test statistic used in not rejecting Ho is the F-test and the result is not significant. Thus, it can be concluded that the two groups have the same variance.

Table 1 further shows the comparison of the performance test posttest means score of the two groups. Thus, the null hypothesis Ho: There is no significant difference between the posttest mean scores of the academic performance of Grade 8 learners taught with video clips enrichment and taught with K to 12 learning modules after the intervention is rejected. Therefore, the result is significant.

It is important to remember that there is a significant difference in two groups in terms of their performance test in their posttest mean scores. It implies that on the average, the academic performance of the students in the two groups based on their posttest scores is not the same. Thus, as shown in Table 1, it can be solely concluded that the group exposed to video clips enrichment has a higher mean compare to the control group. The table implied that the experimental Group performed better in improving their performance in Earth and Space Science as compared to the control group. The improvement in the students' understanding of concepts towards learning could be attributed to the use of video clips. The study of Ontoy (2012) showed that the integration of video clips in teaching science lessons enhanced the academic achievement of the pupils. Pupils could easily remember the lesson because they can visualize the processes involved in the video lessons.

The study of Mirvan (2013) further affirmed that the use of video materials in a classroom can help increase learners' motivation to learn since it can expose them to a wide variety of situations that can help them comprehend similar situations in real-life. The entertainment aspect of presenting the lessons increased their interest in the topics. It boosted the learner's motivation to acquire knowledge since embedded in the video clips were special effects, appropriate sound used, and relevant motion pictures that helped in the increase of learner's interest to learn.

\section{Comparison of the Academic Performance in Earth and Space Science between Groups}

The null hypothesis was tested at 0.05 level of significance using Analysis of Covariance (ANCOVA) to find out if there is a significant difference in the academic performance level in Earth and Space Science between the experimental and control groups. Table 2 shows the summary of data.

The pretest that was applied serves as the covariate. The pretest was given by the researcher to both experimental and control groups before the conduct of the study. It concluded that there was no significant difference between the pretest mean scores of the experimental group and the control group. The posttest was conducted by the teacher to both groups after the treatment.

Table 2

Comparison of the Academic Performance of Grade 8 Learners taught with Video Clips Enrichment and with K to 12 Learning Modules

\begin{tabular}{llllll} 
& Type III sum & df & Mean & F & Sig. \\
\hline Source of square & \multicolumn{4}{c}{ Square }
\end{tabular}

\begin{tabular}{lccccc} 
Corrected Model $31.465 \mathrm{a}$ & 3 & \multicolumn{2}{c}{10.488} & 4.355 & .008 \\
Intercept & 1057.191 & 1 & 1057.191438 .966 & .000 \\
Group & 17.298 & 1 & 17.298 & 7.182 & .010 \\
POST-TEST & 26.418 & 1 & 26.418 & 10.969 & .002 \\
Covariate & 13.792 & 1 & 13.792 & 5.727 & .020 \\
(PRE-TEST) & & & & &
\end{tabular}




Error $\quad 134.868 \quad 56 \quad 2.408$

Total $34248.000 \quad 60$

Corrected $\quad 166.333$

Total

a. $\quad$ R Squared $=.189$ (Adjusted R Squared $=.146)$

The method of ANCOVA was used to take into account the effect of covariant which is the pretest. The pretest is another variable measured that might have influenced the outcome of the dependent variable which is the posttest. The posttest scores of the experimental group taught using the video clips enrichment were weighed against the posttest scores of the control group using the $\mathrm{K}$ to 12 learning modules. The experimental group attained significantly higher in their mean scores compared with the control group.

The data in the table showed the computed p-value which was less than 0.05 level of significance. The academic performance in Earth and Space in Science between students taught using the Video clips enrichment and those students using the K-12 learning modules differed significantly. Since the results of the statistics presented a justification, the null hypothesis of the study is rejected. Thus, the research hypothesis which states that there is a significant difference between the mean gain scores of the academic performance of Grade 8 learners taught with Video clips enrichment and taught with the K to 12 learning modules after the intervention is not rejected.

The current findings are parallel to the claims of Yousef, et al. (2014) who found some evidence that the use of video-based learning saw improvements in teaching methods and learning outcomes. It is also parallel to the findings of Iqbal Shah (2015) who conducted a study on the impact of multimedia-aided teaching on the learner's academic achievement. Results showed that multimedia-aided teaching is more effective than the traditional one. It is more operative for the cognitive and attitude development of the learners than the conventional method. There is a significant difference in the achievement score of both groups. Multimediaaided teaching (MAT) helps to develop higher-order cognitive skills and appeal the learner psyche towards learning. The use of animations, sound, and video and audio clips makes the lessons attractive and affective to the learners.

Furthermore, the study of Kapri (2017) on the impact of multimedia in the teaching of science which concluded that multimedia method proved to be better than the conventional method in the teaching of Science also supports the findings of this study. When the controlled-group learners were taught some concepts of science by the conventional method and the experimental group of learners were taught by a multimedia method, it was found out that the achievement of the experimental group was better than the controlled group in posttest and the acquired retention was better in case of an interactive multimedia method.

\section{Experiences of Grade 8 Learners in Learning Earth and Space Science with Video Clips Enrichment}

The learners were asked about their experiences in learning Earth and Space Science through the use of video clips. The researcher conducted an interview to five randomly selected respondents after the implementation of the study. It consisted of open-ended questions on how they feel on the use of video clips, their feelings during the first video clip session, their impression towards learning through videos, the benefits that they find in viewing video clips, the educational benefits of using this form of technology in the classroom, and the drawbacks of using technology. The learners have various ideas about the different questions presented.

During the interviews, the learners were asked about what they feel when their teacher told them that they would be having his lecture using video clips. These are side questions to support their experiences after they were exposed to teaching with the use of video clips enrichment. It was found out that most of them felt excited about it. This practice of using technology inside the classroom was not the usual kind of method that they are dealing with every day that was why they felt excited when they were exposed to it.

Most of the learners showed a positive response to the use of video clips inside the classroom. According to Greenberg and Zanetis (2012), the use of video is just the beginning to meet the needs of the learners. Video can help educators address the challenge of different learning styles of our children and improve 
the way they absorb, interpret, process and use information. The video is also an essential tool that creates a powerful impact on the retention of information and engagement of the learner.

Eventually, this particular event when using video would result to a role reversal where teachers are now the 'guide on the side' not the 'sage on the stage,' while the flipped material becomes the control of the learner. Khan of Khan Academy (2010), a non-profit educational organization that is geared towards providing free online video lectures said that there was nothing practical that anyone could do about this broken "learning" model but can now deliver on-demand content to any learner for nearly zero incremental cost. He then added that the video content could be paused and repeated as needed and learners can focus on what they need to know without feeling embarrassed to fill in remedial gaps. He concluded that the classroom would be a place for active interaction, not passive listening and daydreaming.

It is clear that these learners have positive impressions of learning science through video clips enrichment. According to these learners, learning through video clips was very encouraging, more engaging, and there are much fun and excitement. Furthermore, the learners learned the lessons well because the use of video clips made abstract topics that once seemed to be difficult to teach but were now more accessible and understandable to learn. With video clips continuing to gain popularity, it seemed only natural that this familiar and widespread platform extends into the education setting.

In the study of Ontoy (2012), he cited that using video clips were beneficial to the learners. Viewing television, video clips, and movies have multiple modes which effectively match with the learner's various intelligence preferences. A video clip engages both hemispheres. The left side of the brain processes the dialogue, plot, rhythm, and lyrics; the right side of it processes the visual images, relationships, sound effects, melodies, and harmonic relationships (as cited by Berk, 2009). Therefore, video clips could be adopted in the classroom as an aspect of instruction together with the other instructional materials prepared for the given lesson.

Learners today made use of educational videos as a tool for learning everything from the latest dance craze to changing a tire. It is remarkable to note that $92 \%$ of the digital video viewing audiences are millennials. Studies have shown that the use of short video clips allows for an efficient processing and memory recall of the learners. The visual and auditory nature of videos would appeal to a wide audience and allows them to process information naturally.

The use of videos in teaching and learning would benefit not only the learners but also teachers and their affiliated institutions. A study conducted by software company Kaltura (2015) concluded that 93\% of teachers believed that the use of educational videos improved the learning experience. They also served to break down barriers, such as learner and campus location, which were once insurmountable.

Using videos in the classroom was a very nice idea. It does not only provide a teacher with a wide range of extraordinary benefits but it also creates a fun experiment for the learners. Videos can easily showcase a virtual 3D images, vivid animations, and unique concepts and so on. It also integrated experiments that are difficult to perform in class or which can put-on quite a lot of danger. On top of that, videos have the power to bring literature, music, history and many other interesting things directly in front of the users. It is fun, easy to do, and it does provide us with a very sufficient value.

As educators, we aimed to get our learners energized and engaged in the hands-on learning process, and the video was an instructional medium that was compelling and could generate a much bigger amount of interest and enjoyment than the more traditional printed material. Video was the perfect medium for our learners to use sight and sound to those who are auditory or visual learners. Video stimulated and engaged them creating interest and maintaining that interest for extended periods. It also provided an innovative and effective means for educators to address and deliver the required curriculum content.

\section{CONCLUSIONS}

The following conclusions were drawn from the findings: The Grade Eight learners taught with video clips enrichment have "very satisfactory" academic performance in Earth and Space Science, hence the learners have developed the fundamental knowledge and skills and core understandings in the lessons, and they can transfer the concepts independently through authentic performance tasks.

There is a significant difference between the mean gain scores of the academic performance of Grade 8 learners taught with video clips enrichment and taught with $\mathrm{K}$ to 12 learning modules after the intervention, therefore, the experimental group achieved significant growth in conceptual understanding which could be attributed to the use of video clips. Thus, the use of video clips could enhance the academic performance of Grade Eight learners. 
The Grade 8 learners taught with video clips enrichment have gained positive experiences in learning Earth and Space Science. Thus, the use of video clips enrichment in learning Earth and Space Science could be used to help develop a very favorable experience towards the subject.

\section{ACKNOWLEDGMENT}

Making this research study is one of the most difficult challenges the researchers have ever faced in life. To the Almighty Allah, all thanksgiving, honour and glory, for giving them wisdom, courage, determination and strength to complete this work despite of all the difficulties.

The researchers could not contain their gratitude to the members of this researchcommittee: Dr. Oscar B. Cabańelez, University President of Bukidnon State University;Dr. Estela C. Itaas, Vice President for Academic Affairs;Dr.Mercidita S. Villamayor, Dean of the College of Education;Dr. Roberto D. Napere Jr., Thesis Adviser;Dr. Edna T. Maganding, the chairperson of the thesis committee; and Dr.Nornie B. Micayabas and Mrs. Katherine Joy G. Reyes.

Also, their heartfelt thanks to all the heads of the schools where they conducted his study: Prof. Ebresamen W. Dipatuan, Assistant Dean of MSU-Integrated Laboratory School; Mrs.AlmiraMingca, Principal of Philippine Integrated School Inc. and the faculty and staff of the school who were very supportive in the conduct of the pilot-test of this study.

Their infinite thanks to their family and friends for the support, understanding, love, care and encouragement that kept them going when they wanted to give up.Their presence is truly remarkable and inspiring to the researchers to finish this piece of work.

\section{REFERENCES}

[1] Bates, A.W. (2015). Teaching in a Digital Age: Guidelines for Designing Teaching and Learning Vancouver BC: Tony Bates Associates Ltd. ISBN: 978-0-9952692-0-0

[2] Berge, Z. (2008). Training Generation N: How Educators should approach the Net Generation. Training Generation N. University of Maryland, Baltimore County, Baltimore Maryland, USA. Retrieved: June 21, 2011

[3] Berk, R. A. (2009).Multimedia Teaching with Video Clips: International Journal of Technology in Teaching and Learning, 5(1), 1-21

[4] Edutopia. (2005, November 5). Retrieved January 18, 2015, from http://www.edutopia.org/technology-integration-guide-description

[5] Enger, J. (1976). Teaching introductory chemistry with videocassette presentations (Report No. 362). Urbana, IL: Illinois University, Office of Instructional Resources. (ERIC Document Reproduction Service No. ED 135362 )

[6] Fabos, B. (2001). Media in the Classroom: An alternative history. Paper presented at the annual conference of the American Education Research Association, Seattle, WA. (ERIC Document Reproduction Service No. ED 454 850)

[7] Fagsao, Jonelle (2019). Indigenous Songs as Instructional Aids in Teaching Mother Tongue to Pupils of Bontoc Central School: Its Educational Implications. International Journal of Science and Management Studies. Volume 2, Issue 3

[8] Greenberg, A. \&Zanetis, J. (2012).The Impact of Broadcast and Streaming Video in Education. Portion Cisco Systems Inc. and portion Wainhouse Research LLC.

[9] Griffin, L. (1998) Using Video in the Classroom. Curriculum Director, Library Video Company. Retrieved: May 7, 2011.http://www.libraryvideo.com/articles/article13.asp

[10] Isiaka, B. (2007). Effectiveness of Video as an Instrumental Medium in Teaching Rural Children Agricultural and Environmental Sciences. International Journal of Education and Development using Information and Communication Technology, Lagos State University, Nigeria.

[11] Iqbal Shah, M. (2015). US-China Education Review, Vol.5, No.5,349-360

[12] Kaltura (2015). The State of Video in Education: A Kaltura Report [White paper]. Retrieved from http://site.kaltura.com/rs/984SDM859/images/The_State_of_Video_in_Education_2015

[13] Kapri, M.(2017). Video as a Tool for Motivation.Technical University of Catalonia, Barcelona, Spain

[14] Khan, S. (2010). Khan Academy Homepage [WWW]. Accessible via http://www.khanacademy.org/ 
[15] Mayer, R. (2001) Multimedia Learning. Cambridge. Cambridge University Press.Retrieved: May 7, 2011.

[16] Mirvan, X. (2013). The advantages of using films to enhance student's reading skills in the EFL classroom. Journal of Education and Practice, 4(13), 62-66.

[17] Ontoy, I. (2012). Academic Achievement in Science of Grade V Pupils with Integration of Video Clips.

[18] Prensky, M. (2001). Digital natives, digital immigrants, part II: Do they really think differently? On the Horizon, 9(6). (Also available from http://www.marcprensky.com/writing/)

[19] Savenye, W.C., \& Strand, E. (1989). Teaching science using interactive videodisk: Results of the pilot year evaluation of the Texas Learning Technology Group project. Paper presented at the annual meeting of the Association for Educational Communications and Technology, Dallas,TX. (ERIC Document Reproduction Service No. ED 308 838)

[20] Urabang, Sarah, Valdez, Anabelie (2019). Learning Modes and Preferences of MAPEH Students: Basis for Designing Learning and Instructional Materials (LIMs). International Journal of Science and Management Studies. Volume 2, Issue 4

[21] Yousef, A.,Chatti,M., Schroeder,U. (2014). The State of Video-Based Learning: A Review and Future Perspectives: International Journal on Advances in Life Science, Vol.6, No.3 \& 4

[22] Zanetis, A. D. (March, 2012). The Impact of Broadcast and Streaming Video in Education. Portion Cisco Systems Inc. and portion Wainhouse Research, LLC 